International Journal of Linguistics, Literature and Translation

ISSN: 2617-0299 (Online); ISSN: 2708-0099 (Print)

DOI: 10.32996/ijltt

Journal Homepage: www.al-kindipublisher.com/index.php/ijltt

\title{
Students' Perceptions of the Consequences of Distance Learning throughout Covid19 Epidemic in Higher Education: The Moroccan Case
}

\author{
Dr. Rym Asserraji 8(D) \\ Assistant Professor of English, Faculty of Sciences, at Moulay Ismail University, Meknes. Morocco \\ $\triangle$ Corresponding Author: Dr. Rym Asserraji, E-mail: rym.asserraji@gmail.com
}

\author{
ARTICLE INFORMATION \\ Received: August 08, 2021 \\ Accepted: September 07, 2021 \\ Volume: 4 \\ Issue: 9 \\ DOI: $10.32996 /$ ijllt.2021.4.9.7
}

\section{KEYWORDS}

Distance learning, Covid19

pandemic, challenges and higher

education in Morocco

\section{ABSTRACT}

Distance learning can be regarded as learning that predominates entirely through the internet. It has been implemented because of the pandemic of Covid 19. According to Chaney (2010: 5-21), it is also referred to as distance learning, which is a swiftly flourishing setting that allows teachers and students and all people working in all domains the flexibility of working beyond the restraints of time and place. Also, this shift from face-to-face lectures to online classes is the only possible solution. Nevertheless, academic institutions would not be capable of converting all of their college curricula into an online resource overnight. Distance, scale, and personalized learning are the three biggest challenges for online learning. Therefore, the purpose of this paper is to shed light on the challenges of online learning for students at the university level. And then to try to find out the possible solutions and recommendations to enhance online learning for the benefit of students.

\section{Introduction}

The disastrous and transmissible disease Corona Virus similarly identified as Covid19 has intensely trembled the worldwide economy. This tragedy has also surprised the education sector, and it is predicted to flow all over the educational zone universally. The Covid19 pandemic outbreak has compelled many schools and colleges to remain locked temporarily. According to scholars' assessment, it is uncertain to get back to normal teaching as social distancing is prevalent in this period and will have damaging effects on learning opportunities. Moreover, educational units endeavour to recollect other alternatives to manage this defying situation, which undeniably entails humanity and unity. There is a thoughtful prerequisite to watch over and protect students, faculty, academic personnel, communities, and the entire state universally (Lehmann, 2004:1).

Distance learning can also be referred to as e-learning, within which various arguments are linked, such as approachability, lowcost, adaptability, learning pedagogy, life-long learning and policy are some of the arguments related to online pedagogy. According to Thomson (2010: 6), it is asserted that the online learning approach is smoothly available and can even reach rural and secluded regions. Learners can manage or program their time for courses accomplishment that is obtainable online. Connecting in-person courses alongside technology offers advancement to unified learning and harmonized classrooms. Such a kind of learning setting can intensify students' learning potential. Students can learn whenever and wherever they yearn, thus emerging up-to-date talents in the process leading to life-long learning. The government also recognizes the rising significance of online learning in this dynamic world.

\section{Literature Review}

Online learning settings can be classified into three leading groups: fully web-based, hybrid format, and outdated courses using web-based supplements.

Fully web-based courses are wholly handled on the Internet with no physical contact. All characteristics of the course are directed in an online learning environment. The hybrid courses are composed of web-based and classroom sessions, with an

\section{K C AL-KINDI CENTER R D FOR RESEARCH AND} Your gateway to world-class research

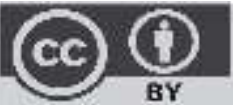

Published by Al-Kindi Center for Research and Development, London, United Kingdom. Copyright (c) the author(s). This open access article is distributed under a Creative Commons Attribution (CC-BY) 4.0 license 
adjusting amount of time assigned to the virtual and in-person sessions, depending on the kind of the class and the willpower of the tutor. The programming structure controls online technology as a means for portraying complementary resources for traditional classroom study. Likewise, it is vital to understand online learning that there is not a specific illustration that would hold all the benefits of online learning settings. Hence, web-based learning environments are as abundant and complex as conventional classroom settings, with each learning environment performing differently to a degree.

Online learning is appealed by students from diverse backgrounds with different academic requirements that conventional education classes are lacking or incapable of accomplishing. The call for the online course is resulting from a hustle "to provide quality education to all students, regardless of location and time" (Chaney, 2010: 5-21)

\section{The Benefits of Online Learning}

Online courses have been perceived to be inspiring to students who prefer self-controlled learning (You \& Kang, 2014:5). In an investigation directed by Kirtman, a student responded to online tasks by clarifying: ' It is self-guided so I can spend more time on the concepts that I need help with and less on concepts that I can pick up quickly' (Kirtman,2009:5). Self- controlled learners tend to exploit countless 'cognitive and metacognitive strategies to accomplish their learning goal'. Learners who are proficient in enhancing their self-controlled learning potential often utilize time management, examine data constantly, solicit assistance from professors or colleagues, accomplish their tasks according to the deadlines, and have the ingenuity of metacognition to improve their personal education. Online learning offers students the capacity to learn at a time and in an area in harmony with their learning requirements. According to Thomson (2010: 6), several teachers and students illustrated their competencies to focus more on the content of the course and less on issues such as parking, traffic, and other problems that may arise when joining a traditional class environment

\section{Features for Achievement}

Research directed by Kirtman revealed online learners examinations that "were so overwhelmingly positive that the issue of students satisfaction cannot be ignored" (2009: 8). Environmental traits like course structure are not only central to assess, but it is imperative to examine key encouragement characteristics as components for an efficient online course and experience in favor of the learner. Self-control and motivation have been classified as two energetic mechanisms for attaining victory in online courses. Self-control can be labelled as "the ability of students to plan, monitor, and evaluate their own behavior, cognition and learning strategies" (Matuga,2009:5-8). Self-control on its own is not sufficient for accomplishing success given that students have got to be intrinsically or extrinsically encouraged to use self-controlling strategies excellently to grow in the academic scope of online courses (Matuga,2009: 8). As observed, self-control is a vital component to succeed in online courses. As a result, non-self-controlled students tended to display academic procrastination, encouraged disorder, and used less cognitive and metacognitive strategies to reach their learning objectives (You\& Kang, 2014:9)

Furthermore, communication is evidently one of the most dominant constituents of an effective online course. Lehmann illustrates "communication is what separates true online learning from Web-based tutorials"(2004:9). In addition to this, collaboration and communication have been classified as fundamental characteristics in the accomplishment of an online course to boost students' achievement and willingness. Collaboration may lead in three fundamental zones: cooperation between the learner and the tutor, the learner and other learners, and the learner and the subject matter (Savenye,2005:9). It is also noteworthy to illustrate that collaboration between the learner and the subject matter is the most recognizable category of collaboration that prevails in online settings throughout debates and evaluations.

Online teachers can organize the class environment to encourage the learner and the tutor and the learner and other learners through synchronous and asynchronous collaborations. There is a number of alternatives for students to learn collaboratively and compassionately with other learners and the tutor in live debates, such as learning through reflective journal entries, peer reviews, discussion boards, and video or audio teleconferencing (Savenye,2005: 9-10)

\section{Methodology}

Since March 16th, 2020, the Moroccan authorities have decided to suspend face-to-face courses in public and private schools and universities in order to comply with the containment measures related to the Covid-19 health crisis. In addition, several measures have been taken to ensure the continuity of students' learning by helping them adapt quickly to this new learning environment. Hence, this paper's major aim is to investigate students' attitudes towards distance learning during the Covid19 pandemic in higher education. 
The questionnaire has been designed as the major data collection instrument. Concerning the questions mentioned in the questionnaire, they are divided into four major categories: information on respondents' academic path, their encountered challenges regarding distance learning continuity, their self-organization for distance learning, and their evaluation of the used te As for the respondents are Moroccan university students enrolled in private and public institutions and universities around Morocco, such as Fez, Meknes, Rabat, Ifrane, and Agadir.

\section{Results}

\subsection{Background Information}

Are you?

54\&nbsp;réponses

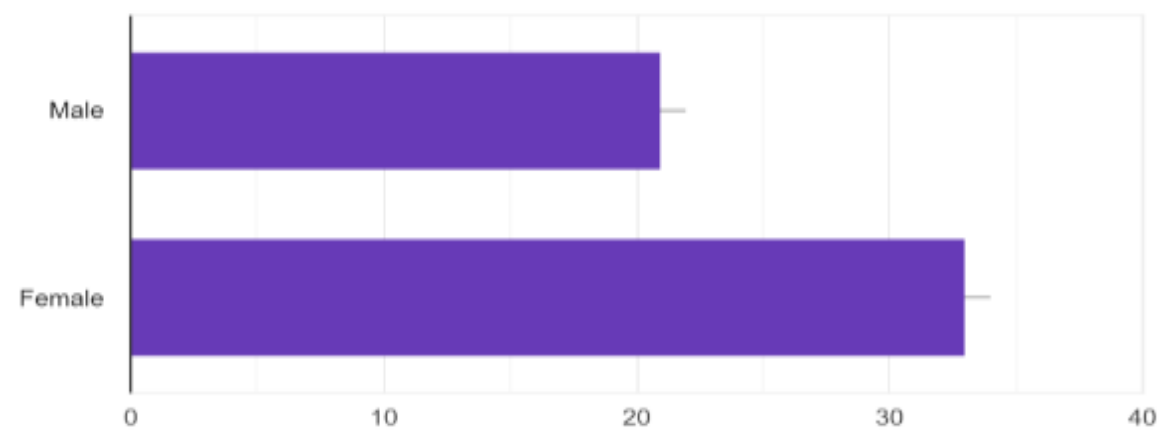

Figure1: Gender

Apparently, it seems that most of my respondents are female students. Their percentage is almost 34\%, whereas male students are $22 \%$

In which region of Morocco, do you pursuit your studies?
54\&nbsp;réponses

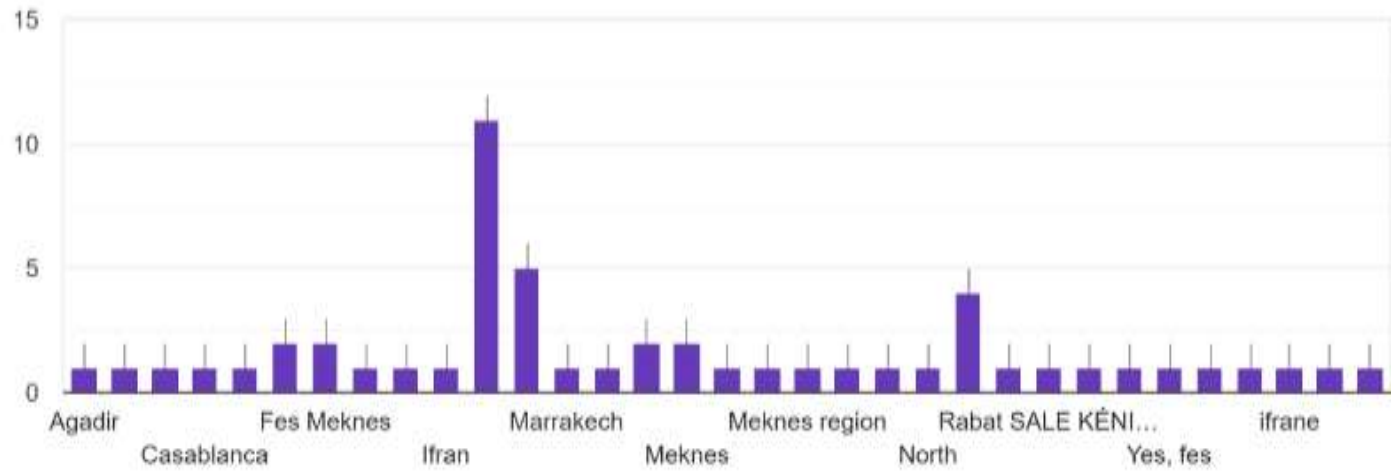

Figure2: The Pursue of Studies during the Confinement Period

It seems that the majority of my respondents pursuit their studies in Ifran $12 \%, 8 \%$ in Marrakech, $6 \%$ in Rabat, and $2 \%$ pursuit their studies in Fez and Meknes too. 
Are you confined in an environment:

saznbspyéponses

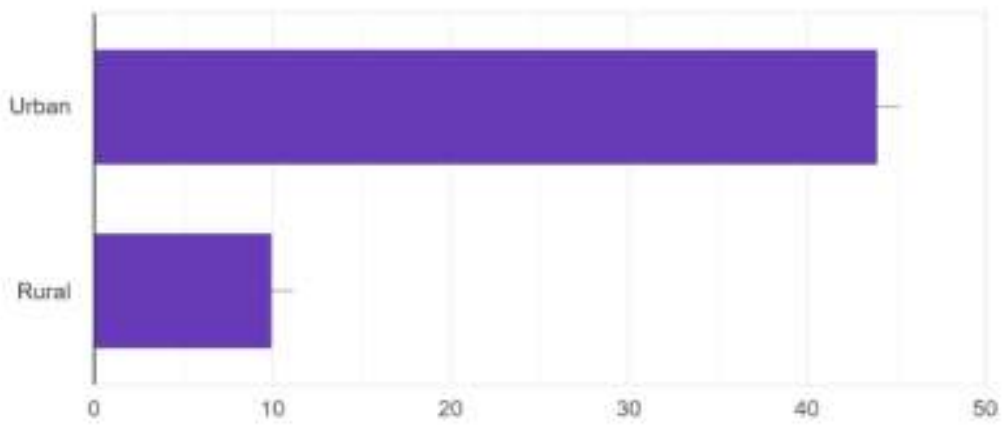

Figure3: The Confinement Area

As far as respondents' confinement is concerned, most of them are lockdown in an urban environment. As seen in the chart above, they are almost $44 \%$ and for those confined in a rural setting, they are around $10 \%$

\subsection{Information on the academic Path}

In which type of institution are you enrolled in?

54\&nbsp;réponses

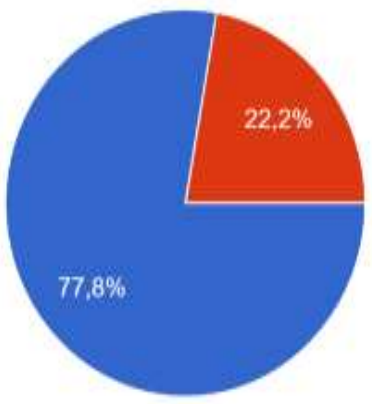

Public

Private

Figure4: Academic Enrollment Institution

Seemingly, $77.8 \%$ are enrolled in public institutions and universities, $22.2 \%$ joined private ones.

You continue your studies in a system of?
548nbspreponees

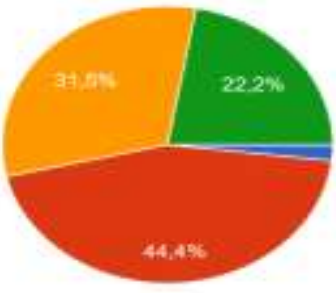

Prkparatory classes.

- Faculty

Higher Schoo

Engineering Cycies

- Vocational Training under the OFPPT

Figure5: The System of the Continued Studies 
Obviously, most of them continue their studies in the faculty $44.4 \%$, whereas $31.5 \%$ joined the higher school and $22.2 \%$ are studying in preparatory classes.

In which discipline?

54\&nbspiréponses

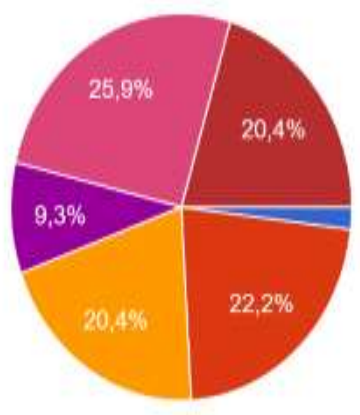

Health Professions (Medicine, Dentistry,

Pharmacy)

Engineering

Science and Technology

Science of Education

Humanities and Social Sciences

Legal Science

Economy and Management

Hospitality, Catering, Tourism

If Other, please justify below

Figure6: The Selected Disciplines

My respondents are pursuing their studies in various disciplines. Most of the $25.9 \%$ are studying economy and management, $22.2 \%$ in engineering, $20.4 \%$ in science and technology and the same percentage have opted for other options of disciplines, and then $9.3 \%$ in humanities and social sciences.

\subsection{Challenges of distance learning continuity}

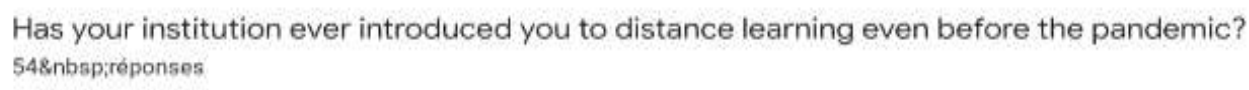

548nbspiréponses

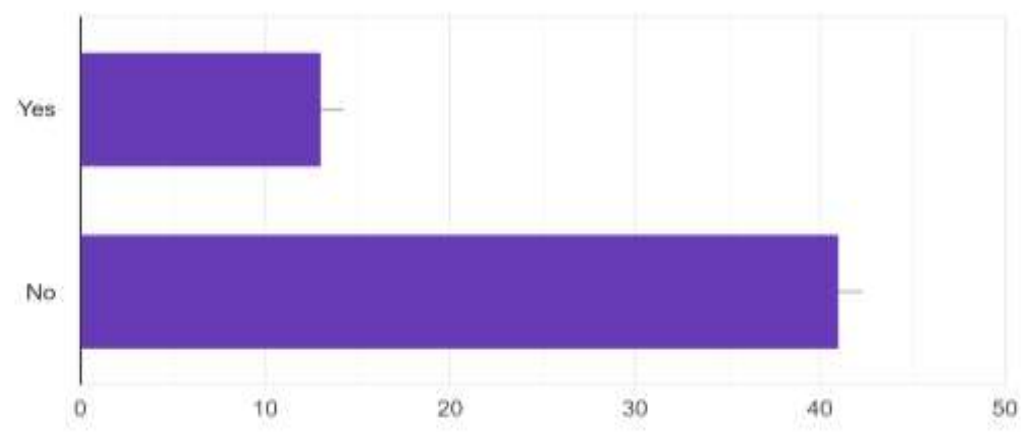

Figure7: The Introduction of Distance Learning before the Pandemic

It is clear that the majority had not been introduced to distance learning before the pandemic. Almost $42 \%$ opted for No and $15 \%$ picked Yes.

One of the respondents says:

'I was very afraid of having a blank year. I could not believe that the face-to-face courses come to an end. Online courses are not as tremendously effective as the face-to-face ones.' 
Following the end of the face-to-face courses, what were your concerns about this?

54\&nbsp;réponses

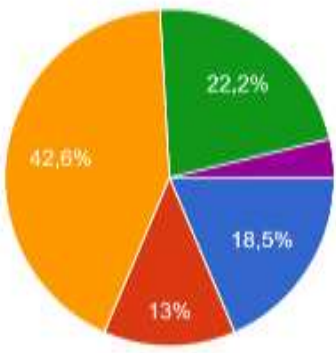

Blank year

Inability to pursue distance education

The way I'm going to take my exams

- Psychological pressure due to external

factors

If other, please justify below

Figure8: Concerned Issues during the LockDown

It gives the impression that $42.6 \%$ are concerned about how they will take their exams, $22.2 \%$ are under psychological pressure due to external factors. In addition to this, $18.5 \%$ are worried about having a blank year and $13 \%$ claimed that they are incapable of pursuing distance education.

\section{During this period of confinement, did you take distance courses?}

548 nbsp;réponsos

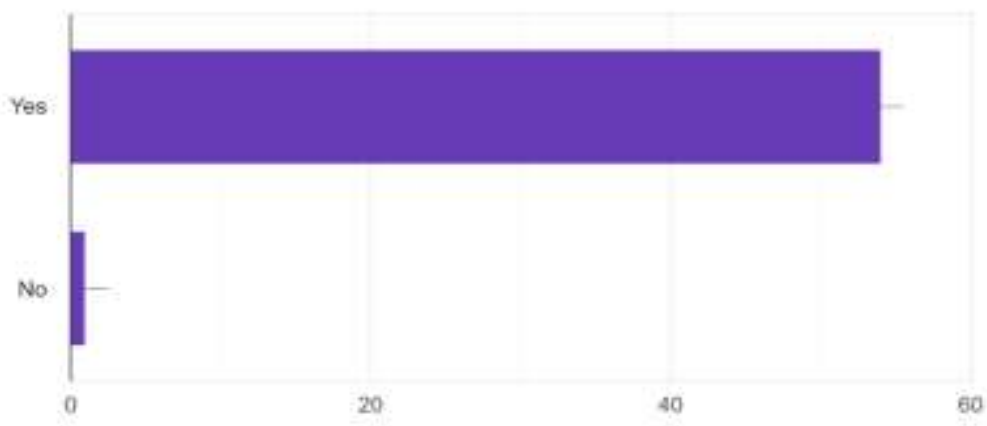

Figure9: Distance Courses during the Confinement Period

It looks that the majority of my respondents took distance courses during the confinement period.

If so, what means did you use?

54\&nbspiréponses

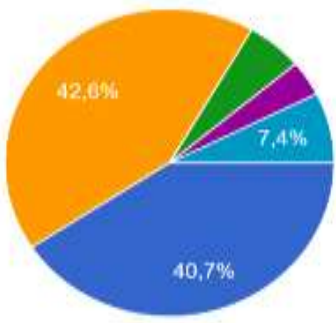

Educational plattorms (Microsott Teams, Google Classroom, Moodle...)

Social networks (Facebook, WhatsApp Instagram, etc.)

Video conferencing tools (Skype, Zoo..

Website of the establishment

Web page or channel set up by your $P$.

Email

- Moroccan television channeis

If other, if justify below:

Figure10: The Used Means for Distance Courses 
40.7\% state that they have used educational platforms, such as Microsoft Teams, Google Classroom, and Moodle, etc. $42.6 \%$ illustrate that they have utilized video conferencing tools like Skype, Zoom, etc. while 7,4\% have opted for an email in addition to others, who have selected the institution website as their main used tool during the confinement period.

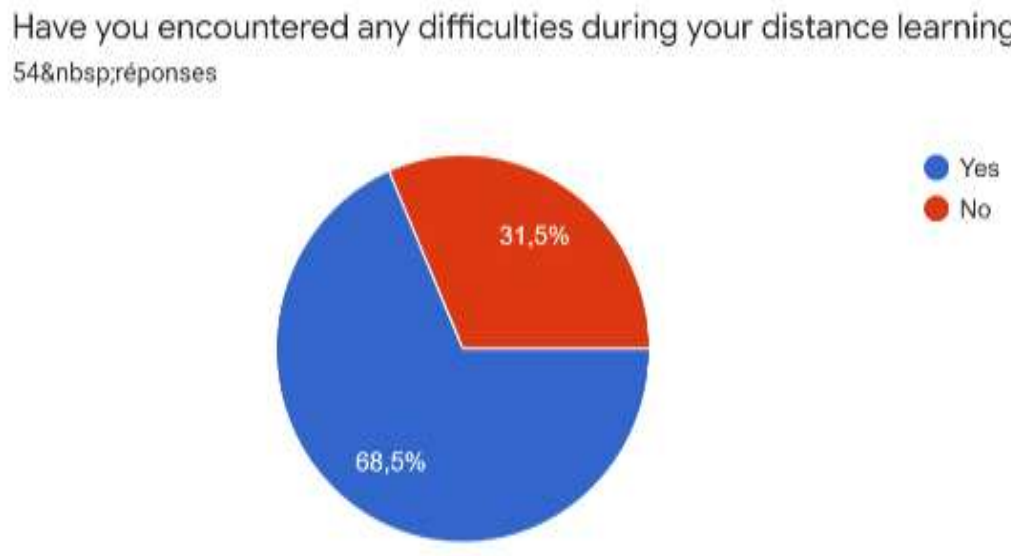

Figure11: The Encountered Difficulties during the Distance Learning Process

$68.5 \%$ argue that they have encountered difficulties during their distance learning process, while $21.5 \%$ did not have any problems.

One of my respondents illustrates:

"I do not have the technological gadgets such as the smartphone and the laptop to pursue my studies online"

\section{If so, what difficulties have you encountered during distance learning? 548nbspréponses}

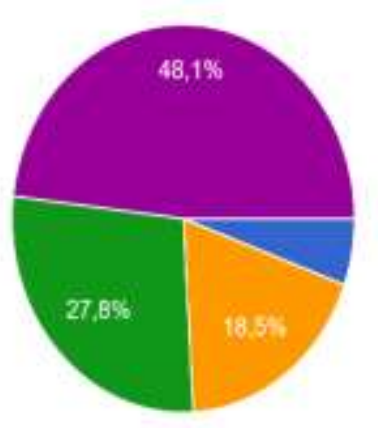

I am not good at using computer applications or smartphones

I don't know how to accoss the plattorms

I have not received any information to follow the courses

I do not have the necessary equipment for distance learning

If other, please justify below

Figure12: The Kind of Difficulties Encountered during the Distance Learning Process

Apparently, it seems that most of my respondents have encountered other problems that are not mentioned in the above chart; whereas $27,8 \%$ claim that they do not have the necessary equipment for distance learning; $18,5 \%$ maintain that they have not received any information to follow the courses while a minority of respondents clarify that they are not good at using computer applications or smartphones. 
Did the tests take place?

54knbspyepanses

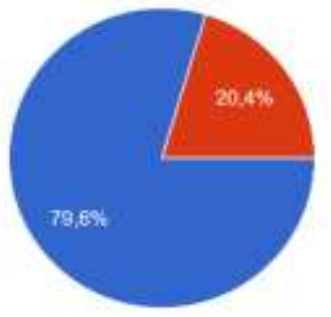

- No

Figure13: The Prevalence of the Tests

79.6\% illustrate that the tests took place in person in their institution, while $20,4 \%$ state the opposite.

One of the respondents argues:

'Even though we were not well-prepared for the tests, we had to sit for them in our institution. Attendance was a must; otherwise, we will be marked absent'

If yes, in which format?
s48nbsp;reponses

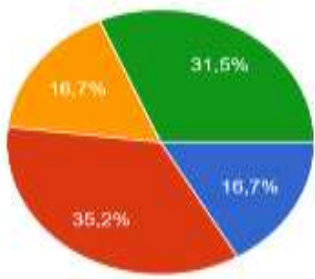

Mini Project

Video Conferenoing Presentation

- If other, please justify below

Figure 14: The Major Format of the Tests

Apparently, most of my respondents state that they took the test in the form of multiple-choice questions, $31.5 \%$ opt for other forms that have not been specified. In addition to this, there is an equality of percentages between the two alternatives, which illustrates that respondents took their tests in mini projects and video conference presentations.

In general, are you satisfied with distance learning?

54\&nbspréponses

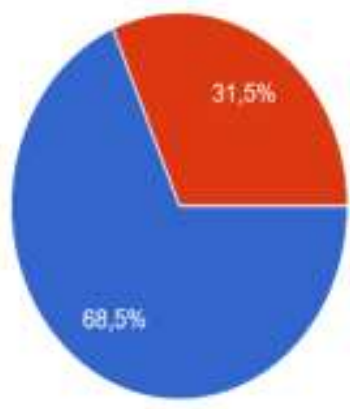

1- No, Not at al

2. Yes, pertecthy

Figure15: The Satisfaction with Distance Learning 
Seemingly, $86.5 \%$ maintain that they are not satisfied with distance learning, while $31.5 \%$ Illustrate that distance learning has been beneficial for them to a great extent.

\subsection{Self-organization for distance learning}

On average, how much time do you spend in your distance learning activities per a day?

548nbspiréponses

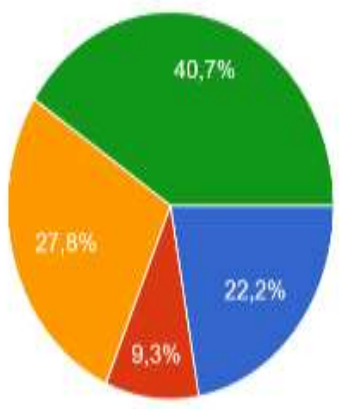

[0-30min]

$[30 \mathrm{~min}=1 \mathrm{~h} 30]$

$[1 \mathrm{~h} 30-3 \mathrm{~h}]$

More than 3 hours

Figure16: The Time spent during Distance Learning Activities per a Day

The majority claim that they spend more than three hours per day in their distance learning activities, while $27.5 \%$ opt for one hour and a half to three hours per day. Besides, $22.2 \%$ spend only thirty minutes per day, which is not enough in their online learning process. Lastly, $9.3 \%$ opt for thirty to one hour and a half.

\section{Does a member of your institution/family accompany you during your learning process during this period? \\ 54\&nbsp,rêponses}

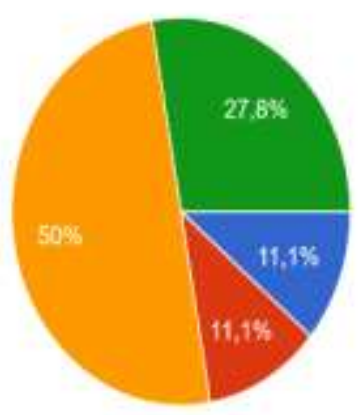

Yes, entirely

Yes, partally

No, I don't need acoompaniment

No, they don thave time to help with me

Figure17: Institution/Family Accompaniment in the Learning Process during the LockDown

It appears that $50 \%$ of respondents believe that they do not need accompaniment from a member of their institution or family during their learning process during the confinement period, while $27.8 \%$ illustrate that their teachers and classmates do not have time to assist them. Besides, it is shown in the above graphic that two alternatives have received the same percentages, which is $11.1 \%$ for each, revealing that a minority of respondents have been supported by their closest friends, classmates, and teachers. 
How do you organize yourself in your distance learning activities?

548 nbap,réponses

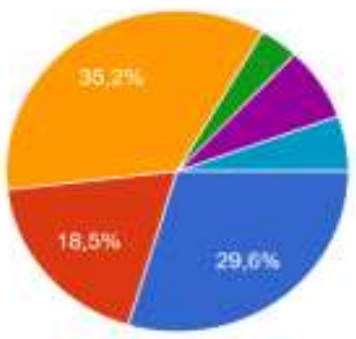

I prepared a space at home dedicated to learning my courses

- i set myseif a daily schedule

I I try to stick to the schedule set by my teachers/institution

I regularty chock the resources availabie to leam at home.

I communicate with classmates who are likely to motivate me to learn.

- If other, please justify below

Figure18: Organization during Distance Learning Activities

Actually, most respondents argue that they try to stick to the schedule set by their teachers and the institution while $29.6 \%$ claim that they prepare a space at home dedicated to learning their courses. In addition to this, $18.5 \%$ try to set a daily schedule.

What is the support used during your online learning?

548nbap;reponses

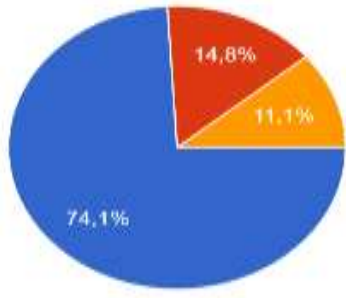

Laptop

Deaktop Computer

- Smartphone

- Tablet

- Smart TV

- If other, please justify below

Figure19: The Support Used during Online Learning

74.1\% claim that they used their laptops in their online learning during the confinement period, while $14.8 \%$ used desktop computer and $11.1 \%$ had access to their smartphones.

\section{Have you had any problems taking your courses remotely because of your Internet connection? \\ 54snbspréponses}
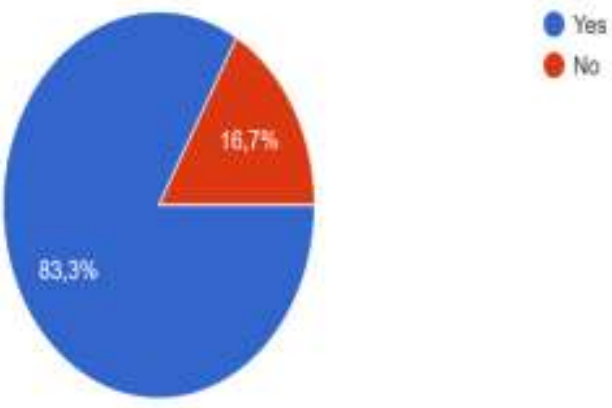

이

Figure20: Online Course Problems because of Internet Connection Apparently, the majority claim that they faced many problems during their online learning process due to internet connection, while $16.7 \%$ have not had problems related to an internet connection. 
If yes, specify the type of difficulty:

548nosprepanses

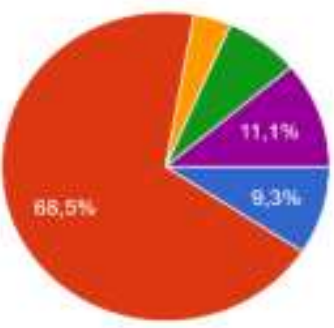

Problem with internet coverage

Low inturnet Speed

Sharing the Internet who family members

intemet Pricing

If other, please justify beiow

Figure21: The Type of Difficulty because of Internet Connection

Most of them clarify that the type of difficulty might be centered on low internet speed while others opt for various difficulties, such as internet pricing. Sharing it with family members may reduce its effectiveness in addition to problems with internet coverage.

\subsection{Evaluation of the used teaching platform}

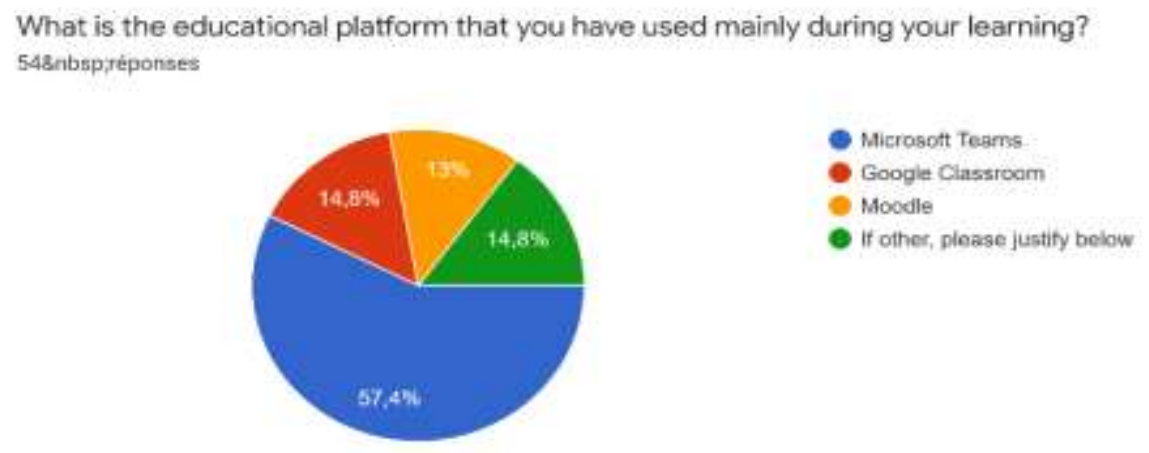

Figure 22: The Educational Platform Used mainly during Online Learning

It seems that $57.4 \%$ have used Microsoft Teams as their major educational platform during their learning process while others have used Google Classroom 14.8\% and Moodle 13\%

One of my respondents states:

"We have used Microsoft Teams platform at AUI university since the beginning of the lockdown"

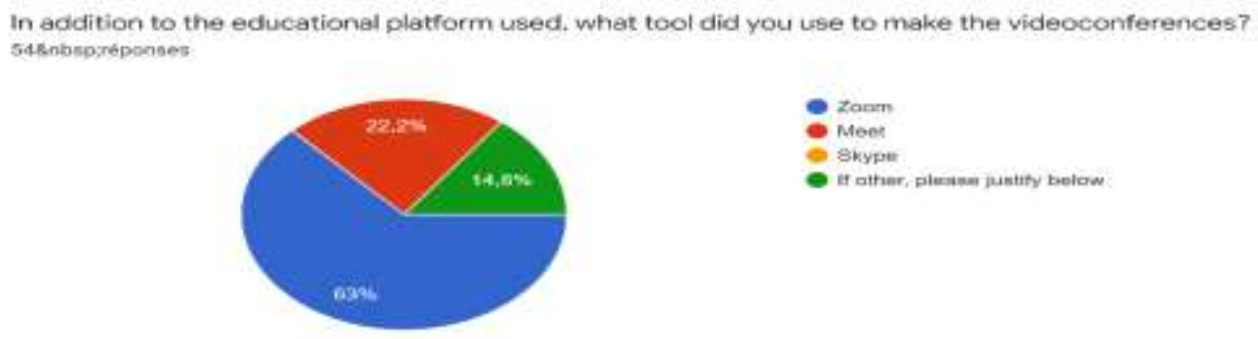

Figure 23: The Used Tools to Make the Videoconferences 
Apparently, most of the respondents have used Zoom as their major tool for making the videoconferences; whereas, $22.2 \%$ have access to Meet and $14.8 \%$ have opted for other unspecified tools.

\section{Based on your experience, what are the strengths of the educational platform? 548 intspitéponses}

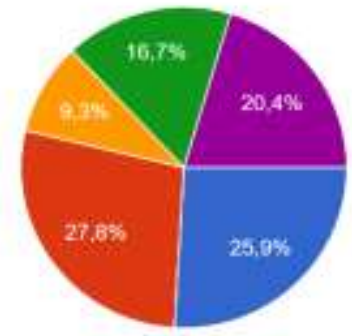

Collaboration

Synchronous Communication (Chet)

Asynchronous communication if Forum, Messaging)

Integratend Video Confernncing

Ongoing avelability of courses

Figure24: The Strengths of the Educational Platform

The majority illustrate that synchronous communication is the main strength of the educational platform, while $25.9 \%$ have opted for collaboration, $20.4 \%$ have chosen the ongoing availability of courses, $16.7 \%$ for integrated video conferencing , and $9.3 \%$ for asynchronous communication.

One of them says:

'The benefits of the educational platform is that it allows us to communicate and chat directly although virtually with our classmates and teachers as well'

Based on your experience, what are the strengths of the platform used?

548nbspiréponses

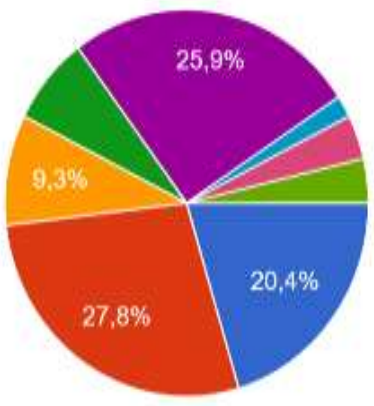

Usability

Ease of use

Speed

Compatibility

Documentation

Availability of user tutorials

Maintenance and updating

Security and stability

Figure25: The Strengths of the Used Platform

Actually, it appears that the majority believes that the major strengths of the used platform is its ease of use, $25.9 \%$ have chosen documentation, $20.4 \%$ have opted for its usability, and $9.3 \%$ have selected its speed.

One of my respondents argues:

'I hope that the educational platform will be part of the educational system after the lockdown' 
For you, how did the platform used contribute to the continuation of your learning? 548nbsp;réponses

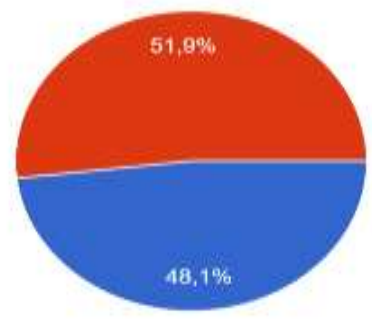

- No contribution

2- Very significant contribution

Figure26: The Contribution of the Used Platform to the Continuation of Learning

It seems that the majority claims that the used platform contributed significantly to the continuation of their learning, while $48.1 \%$ state the opposite.

One of them illustrates:

'We have access to our courses and we can download the documents of the subjects set by our teachers to be ready for exams'

\section{Will you continue to use this platform proposed by your institution after the period of confinement? \\ 54\&nbsp;réponses}

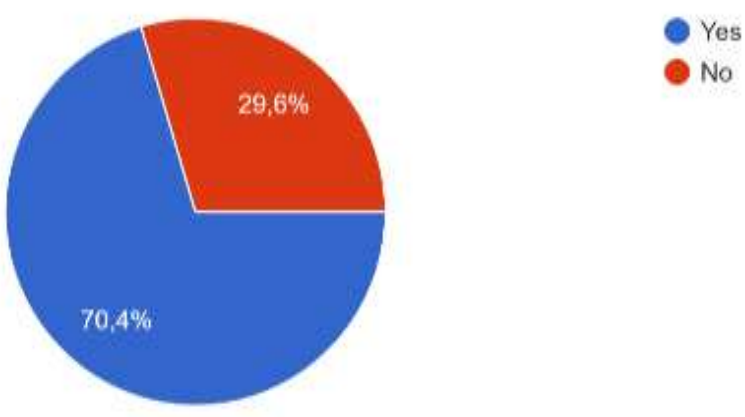

Figure27: The Continuity of Using the Proposed Platform after the Confinement Period

$70.4 \%$ of the respondents illustrate that they will continue to use the platform proposed by their institution after the period of confinement.

\section{Discussion}

The respondents' findings can be classified into three categories. As far as the challenges of distance learning continuity, the respondents reveal that they had not been introduced to distance learning before the pandemic. They had been very concerned about how they will take their exams to the extent that they thought they would be having a blank year. They illustrate that they have taken distance courses through various educational platforms, such as Microsoft Teams, Google Classroom, Moodle, and Videoconferencing tools like Zoom, Skype, and the institutions' websites. Besides, most of them confirm that they had encountered various obstacles during the learning process, such as their inability to use computer applications effectively, the lack of the required equipment for distance learning, in addition to the fact that there is no information on how to follow the courses.

Concerning the respondents' self-organization for distance learning, they state that they have spent more than three hours per day. They had tried to organize themselves in their distance learning activities by attempting to stick themselves to the schedule 
set by their teachers and the institutions and by preparing a space at home dedicated to learning their courses. They claim that the major supporting technological tools used during their online learning are the laptop, the computer desktop, and their smartphones as well. In addition to this, they have also faced internet connection problems, such as low internet speed, issues with internet coverage, and their high cost.

For the evaluation of the used teaching platform, the educational platforms used during students' learning are mainly Microsoft Teams, Google classroom, and Moodle. The strengths of the educational platforms are as follows: synchronous communication, collaboration, the ongoing availability of courses, and integrated video conferencing. The respondents believe that the platform's strengths can also be manifested in its speed, ease to be used, documentation and usability as well. They confirm that they will continue to use the educational platforms after the confinement period.

\section{Conclusion}

It can be deduced from the findings that distance learning can be reflected as learning that prevails all through the internet. It has been executed by reason of the pandemic of Covid19. According to several scholars, distance learning is a speedily booming setting that permits teachers and students and all people working in all fields the flexibility of working beyond the limits of time and place

Furthermore, the purpose behind this article is mainly to examine students' perceptions towards distance learning during the Covid19 pandemic in higher education. The questionnaire has been designed as the main data collection instrument in order to carry out the investigation and it had included a number of categories, namely, the respondents' challenges of distance learning continuity in which they revealed that they had not been introduced to it and they were very concerned in the sense that they thought that they might have a blank year.

Moreover, the majority reinforces that they had confronted diverse barriers during the learning process, namely, their incapability to use computer applications excellently, the lack of the prerequisite tools for distance learning, besides the fact that there was no knowledge on how to follow the courses.

Besides, the respondents' self-organization for the distance learning category claimed that they had devoted more than three hours per day. They had attempted to abide by the schedule set by their teachers and the institutions, as well as by organizing space at home for learning their courses. In addition, they illustrated that the major encountered issue regarding this category was related to the internet connection, such as low internet speed, issues with internet coverage, and their high cost.

Concerning the assessment of the used teaching platform, the investigation had revealed that the educational platform used during students' learning were mostly Microsoft Teams, Google classroom and Moodle for both the private and the public sectors at the university level in Morocco. Lastly, as far as the strengths of the educational platforms, they were centred on synchronous communication, collaboration, the constant accessibility of courses, and the joined video conferencing. The majority of the respondents assumed that the platform's strengths could be demonstrated in its swiftness, documentation, and usability.

It can be concluded that according to all the previous findings, distance learning was not totally effective for students in their learning process and this might lead to another upcoming investigation related to teachers' attitudes towards the same theme. Also, some of the respondents had recommended that distance learning be an addition to the learning process along with the in-person learning process that involves the teachers, the textbooks, and settings for a successful interaction and results.

\section{Acknowledgements}

I would like to thank my respondents for their pertinent feedback and for devoting their time to filling in the questionnaire designed for the accomplishment of the study since this research paper could not have been achieved without their support.

\section{About the Author}

Dr. Rym Asserraji is an sssistant professor of English at the faculty of Sciences, at Moulay Ismail University in Meknes city in Morocco. Her major research areas are centered on applied linguistics, sociolinguistics, gender studies and cultural studies. 


\section{References}

[1] Chaney E. G. (2001). Web-based instruction in a Rural High School: A Collaborative Inquiry into Its Effectiveness and Desirability. NASSP Bulletin, 85(628), 20-35.

[2] Kirtman, L. (2009). Online versus in-class courses: An examination of differences in learning outcomes. Issues in Teacher Education, 18(2), 103-116. Retrieved from http://search.proquest.com/docview/233320851?accountid=27700.

[3] Lehmann, K. (2004). How to be a great online teacher. Lanham, Md: Scarecrow Education.

[4] Matuga, J. M. (2009). Self-regulation, goal orientation, and academic achievement of secondary students in online university courses. Journal of Educational Technology \& Society, 12(3), 4-n/a. Retrieved from http://search.proquest.com/docview/1287037464?accountid=27700

[5] Thomson, L. D. (2010). Beyond the Classroom Walls: Teachers' and Students' Perspectives on How Online Learning Can Meet the Needs of Gifted Students. Journal of Advanced Academics, 21(4), 662-712. http://joa.sagepub.com.pluma.sjfc.edu/content/21/4/662.full.pdf + html

[6] You, J. W. , \& Kang, M. (2014) The role of academic emotions in the relationship between perceived academic control and self-regulated learning in online learning. Computers \& Education, 77, 125-133. 